\title{
Experimental Analysis of Attitudes: The Factorial-Survey Approach
}

\author{
Sergio Herzog \\ Department of Criminology, Safed College, Safed, Israel \\ Email: Sergio.Herzog@mail.huji.ac.il
}

How to cite this paper: Herzog, S. (2017) Experimental Analysis of Attitudes: The Factorial-Survey Approach. Open Journal of Social Sciences, 5, 126-156. http://dx.doi.org/10.4236/jss.2017.51011

Received: December 8, 2016

Accepted: January 13, 2017

Published: January 16, 2017

Copyright $\odot 2017$ by author and Scientific Research Publishing Inc. This work is licensed under the Creative Commons Attribution International License (CC BY 4.0).

http://creativecommons.org/licenses/by/4.0/

\begin{abstract}
A reading of the studies having been published by important sociological and criminological journals reveals a clear picture: for a variable to be considered dependent in a randomized experimental study (at least for those accepted and published by these journals), it has to be behavioral. The question asked in this article is, may only behavioral measures constitute dependent variables in highly qualified experimental studies? The answer is a distinct "no", and attitudinal measures are also proposed as possible and legitimate dependent variables in randomized experimental studies. Here the factorial-survey approach, a relatively new survey technique, which combines the benefits of controlled, randomized experimental designs and conventional surveys, is suggested as a characteristic experimental technique in such studies. This article concludes that the factorial-survey approach may be considered an appropriate experimental technique in social science research-it produces findings that less developed methods are not able to examine.
\end{abstract}

\section{Keywords}

Experimental, Survey, Factorial Approach

\section{Introduction}

The purpose of the present study is to present the factorial survey technique, considered by social scientists as the most advanced survey methodology in social sciences, allowing the researcher to analyze influences of diverse independent variables on the main dependent variable aimed to be analyzed.

As introduction, it could be pointed out that a review of many leading criminological journals ${ }^{1}$ reveals a clear picture: for variables to be considered dependent (that is, the measurable criterion) in randomized experimental, and also quasi-experimental, studies in criminology and criminal justice-at least for 
those accepted and published by them-, they need to be, in the great majority of cases, behavioral. In other words, respondents need to act or behave in a certain, visible, external way, and the researchers need to measure their actions by giving them numbers (for some examples, see Hough, 2010 [1]; Sampson, 2010 [2]; Sherman, 2009 [3]). ${ }^{2}$

Briefly we may define a randomized experimental study as this whose internal validity is established by random allocation of the population of interest-or a sample of it-to different conditions, treatments, or programs. Their common aim is to isolate effects on the respondents, from other possible factors, that may contribute to group differences. In this context, internal validity refers to a researchers' ability to determine whether the research intervention/s (independent variable/s) did in fact cause the change in the measurable criterion. As a result, random allocation of respondents among different treatment programs is the key characteristic of experimental studies, and it ensures that there is no systematic bias that divides subjects into treatment and control groups. Accordingly, subsequent differences found in the dependent variables may then be assumed, with a very high degree of certainty, to stem from the respondents' exposures to the various options of the independent variables, and not from other confounding factors. For this reason, internal validity is often maximized in experimental studies, which are generally considered the most appropriate research setting for questions and issues of causality and effect (see Lum \& Yang, 2005: p. 192 [9]).

\section{The Present Study}

The question asked in this study is-in the author's view-very straightforward: may only behavioral measures constitute dependent variables in highly qualified criminological experimental studies? The answer given by this research, as shown later, is a distinct "NO:" it would suggest that in addition to (clearly not in place of) behavioral measures, also attitudinal-non-visible and internally mental-measures may constitute possible and legitimate dependent variables in randomized experimental studies in criminology; thus the use of experimental designs for these variables needs to increase.

In this regard, the factorial-survey approach, a survey technique (detailed later), which combines the benefits of experimentally controlled, randomized experimental designs, and conventional surveys, and already applied-not very often-, to the analysis of criminological attitudinal data, such as fear of crime, perceived seriousness of offenses, preferred punishments for crimes, and other beliefs or attitudes related to crime, is proposed by this chapter as a fully characteristic experimental technique in criminological studies. Thus, I will argue that

${ }^{1}$ Among them see (in alphabetic order): the British Journal of Criminology, Crime and Justice, Criminai Justice and Behavior, Criminology, Journal of Criminal Law and Criminology, Journal of Experimental Criminology, Journal of Interpersonal Violence, Journal of Quantitative Criminology, Journal of Research in Crime and Delinquency, Justice Quarterly, Law and Human Behavior, and Law and Society Review.

${ }^{2}$ As a random and non-representative sample of such articles see for example: Davis, Maxwell \& Taylor (2006; [4]); Goldkamp \& White (2006 [5]); Koehler \& Thompson (2006 [6]); Matthieu \& Ivanoff (2006 [7]); and Topalli (2005 [8]). 
the factorial survey approach should be considered to be on par with experimental behavioral research (rather than other attitudinal research, using less developed methods, such as poll data or simple scenarios surveys).

The main reason for this claim is based on the ability of the factorial approach to randomly manipulate (control for) the values of dimensions (independent variables) in scenario questions, that are theoretically believed to influence respondents' attitudes (dependent variables). As shown later, this feature is essentially like randomly assigning respondents to multiple "treatments", or the equivalent of randomly assigning experimental subjects to treatment (and control) groups.

As shown in the following, this study is based on three different methods poll data, concrete scenarios, and the experimental factorial research survey -, ordered from the less to the more developed approach, usually applied in social science research to analyze public attitudes. In the opinion of this study's author, it will show that the factorial technique allows us to go much beyond simpler survey methods for analyzing attitudes, producing findings that the other two approaches are not able to examine.

By way of introduction, I'll begin with a brief description of the topic of attitudes, and also research on them, and after it will follow a critical view of the aforementioned three main research techniques, typically applied for the empirical analysis of attitudes, both in criminology and other social sciences.

\section{Scientific Research on Attitudes}

A considerable body of social science research-both psychological, sociological, economic, and also criminological—deals with the assessment and analysis of attitudes, both of the public at large, and/or of social groups in it (see Ajzen \& Fishbein, 1980 [10]). Despite the relative importance of the concept of attitudes in this area of research, it is important to state here that it has had a variable status in it. On the one hand, in a famous quote, attitudes were described as the "primary building stone in the edifice of social psychology" (Allport, 1968: p. 63 [11]); thus the empirical research on them can be defined as central. On the other hand, especially some years ago, some social scientists (see among others Calder \& Ross, 1973 [12]; Wicker, 1969 [13]) were more inclined to agree with the suggestion that it might be much more desirable to abandon completely the attitude concept. This disenchantment with attitudes stemmed mainly from the evidence that attitudes failed to predict behavior in a variety of circumstances. ${ }^{3}$ Despite this suggestion, it should be added here that empirical research on attitudes in social sciences has flourished in recent years.

When people in general, and researchers in particular, question about someone's attitudes, they usually refer to someone's beliefs and feelings related to a person or persons, an event or events, and the resulting behavior tendency

${ }^{3}$ Note that this finding is not limited to visual stimuli (as used in Zajonc's original demonstration), but has also been observed with: auditory (Heingartner \& Hall, 1974 [14]), and even food stimuli (Crandall, 1970 [15]), and it has been applied to varied domains (e.g., to advertising, Sawyer, 1981 [16]; to food preference, Pilner, 1982 [17]; and even liking for rock-and-roll music, Zajonc, 1968 [18]). 
(Ajzen \& Fishbein, 1980 [10]). Taken together, favorable or unfavorable evaluative reactions toward something - whether exhibited in beliefs, feelings, or inclinations to act-define a person's attitude (Olson \& Zanna, 1993 [19]). Thus, unlike behavior that is observable, visible, and then empirically measured, an attitude exists only in a person's mind: it is only a mental state.

Operationally, we can define an attitude: first, as a personally positive or negative psychological evaluation or judgment toward an evaluated object-the "attitude object" in attitude theory; second, as a set of mental beliefs we hold in relation to it; and third, as the providing of a subjective value to it, from a scale of values (e.g., Zanna \& Rempel, 1988 [20]). In other words, an attitude is basically a mentally personal predisposition, or a behavioral tendency, to respond to a particular object, in a generally favorable or unfavorable way (Ajzen, 1982 [21]). Based on these definitions, we can understand why both politicians, lobbyists, products' manufacturers, and also sellers, spend billions of dollars every year trying to create favorable attitudes toward their ideas or products. ${ }^{4}$

Generally, the evaluative component of an attitude can be thought of as having both a direction (either positive or negative), and an intensity (ranging from very weak to very strong feelings). Accordingly, attitudes are seen as providing an efficient way to size up the world, and they influence the way in which a person perceives and responds to it (Allport, 1935 [22]; Thomas \& Znaniecki, 1918 [23]). For example, when we have to respond to a question, both quickly and deeply, the way we feel about the object included in the question can guide our perception regarding how we react toward it (Ajzen \& Fishbein, 1980 [10]). Only as an example, a person who believes a particular ethnic group is lazy and aggressive may feel dislike for such people, and therefore may intend to act toward members of it in a discriminatory or negative manner.

In addition, it should be noted here that attitudes also influences attention and behavior: on the one hand, a person who likes, for example, Woody Allen's movies will be more likely to notice news stories about Allen's activities; on the other, a person who opposes certain proposal from the government will be more likely to participate in a demonstration against it.

Where do attitudes come from? How are they formed? The answer lies in the processes of social learning or socialization. Attitudes may be formed: first, through reinforcement, that is, by instrumental learning, based on direct experience with the object, through associations of stimuli and responses; second, through classical conditioning, that is, a neutral stimulus gradually acquires the ability to elicit a response through repeated association with other stimuli that elicit that response; or/and third, by observing (significant) others-this mechanism is defined as observational learning, by which another source of attitudes is the social environment-parents, siblings, family, teachers, community leaders, and also the media, especially television and films (Ajzen \& Fishbein,

${ }^{4}$ One of the important problems in this area is the use that politicians and policymakers often make of the results of such surveys, in order to justify a certain policy on the basis of "this is what the people want." The problem is that such surveys reveal only a superficial part of public opinion, so policymakers decide without having the whole picture. 
1980 [10]).

Basically, when we assess attitudes, we tap three dimensions on them: affect (feelings) toward the evaluated object, behavior tendency toward it, and cognition (thoughts) on it. It should be noted there that because attitudes are an important influence on people, they occupy a central place in social sciences. Thus, if we want to understand basically, by social research, how people behave, we need to know why they behave in such ways. Moreover, since attitudes form the core of our self-concepts, and our beliefs about ourselves, politics, our jobs, our hobbies, and everything else that we do or know, it seems logical that they are what we need to look at, if we are to predict and explain behavior.

In addition, if we can assess and understand the attitudes people hold, and why they hold them, then we should be able to predict, for example, when people: will help others, will be aggressive or prejudiced, will engage in healthy behaviors, and will buy some products, but not others. Accordingly, attitudes are at the core of social sciences, and among them also of criminology, because they should be the construct that enables us to predict how people will behave in the future (Ajzen \& Fishbein, 1980 [10]).

Research on the consistency between individuals' attitudes and behavior toward an object has focused on the identification of variables that moderate the extent of the observed relation. This approach, which has been referred to as the When? generation of research, due to its focus on the issue of when attitude scores are predictive of later behavior (e.g., Zanna \& Fazio, 1982 [24]), has produced considerable progress. A variety of situational variables, personality factors, and qualities of the attitude itself, have been already identified, as moderators of the attitude-behavior relation (for a comprehensive review on this topic see Fazio, 1986 [25]).

\section{Empirical Research on Attitudes}

The attitude objects that are commonly studied in attitude research include: individual persons, behaviors and classes of behaviors, objects, events, or issues, as well as social policies and social groups (e.g., Ajzen, 1988 [26]; Eagly \& Chaiken, 1993 [27]). Generally, attitudes can be positive or negative toward the evaluated objects, or we can simply have opinions about them without any strong emotional commitment. According to the psychological literature on attitudes, we tend to develop more positive feelings towards objects and individuals the more we are exposed to them-the mere exposure effect (see Zajonc, 1968 [18]). In this regard, no action or interaction with the object is required, and we do not need to possess or even develop any explicit beliefs about the object.

The implications of this finding are considerable and wide-ranging. For example, it suggests that familiarity does not, as the old adage says, breed contempt, nor does absence make the heart grow fonder. On the contrary, it appears that, quite simply, the more we see something, the more we like it. There have been many replications of the mere exposure effect (see only as an example, Mita, Dermer \& Knight, 1977 [28]), and many reviews of the literature, and also 
meta-analyses, have confirmed that it is a highly pervasive and robust phenomenon (see Bornstein, 1989 [29]). In sum, the mere exposure effect appears to be an important way in which attitudes can form.

It is important to state here that a particular attitude toward an object does not exist in isolation. The person who believes, for example, that government spending causes inflation, has usually a whole set of beliefs about the role of government in the economy, and his/her attitude about spending is related to other beliefs, such as whether the government needs to intervene in private economic issues.

Generally, people express their attitudes constantly during their lives, that is, they award values, more or less consciously, to: objects, action, other people or groups, institutions, ideas, etc., and then indicate the measure of their preferences in relation to the options before them. In fact, life itself may be defined as a series of evaluative tasks or choices: most of the time we are occupied in deciding what to do at a given moment, and weighing up our options in every situation. Of course, some of these choices are not especially important, and we may decide on them automatically (e.g., how to travel from home to work; what to wear). These choices are mostly based on past personal experience, and with time they become habits.

However, it should be emphasized here that unlike the former decisions, several of our choices have important implications for us and others close to us; for these choices we usually measure alternatives. In decisions such as whether or not: to marry someone, to accept a job offer, to buy a particular house or car, we usually consciously weigh the positive or negative aspects or characteristics of these matters, while making up our minds. In other less important cases or situations, decisions are not based on deep considerations, but seem more to be determined by a sudden intuitive "flash" (e.g., Ajzen, 1988 [26]; Bargh, 1997 [30]; Eagly \& Chaiken, 1993 [27]).

\section{Research Methods on Attitudes}

How do we measure a person's attitudes? As an internal state, an attitude is not directly observable, and we cannot study psychological predispositions directly. Instead, for analyzing them we must rely on various measures, which reflect a person's attitudes, and infer from them evaluative responses to questions of some degree of favorability or unfavorability. A considerable body of research, also in criminology and criminal justice, tries to assess and analyze these attitudinal evaluative and choice processes. Overall, despite the high heterogeneity of the techniques and methods applied in such studies, this chapter categorizes them into three different and separate approaches. From the least to the most sophisticated approach, these include: poll data, the simple scenario, and the factorial survey approaches, and they are described next.

\subsection{The Poll Data Approach}

As with any public issue, also attitudes to crime and judicial issues, can be assessed 
by means of poll data (see Green, 2006 [31]; Lynch, McGurrin \& Fenwick, 2004 [32]; Tyler \& Wakslak, 2004 [33]; Vollum, Longmire \& Buffington-Vollum, 2004 [34]). This kind of surveys is usually published in the media, and it is usually used when exist monetary or time constraints. Usually such polls measure attitudes along a bipolar dimension, that runs form highly favorable to highly unfavorable, toward the attitude object. Accordingly, such polls tend to be formulated in overly simplistic formats, often referring to global, unspecific, undifferentiated categories (also around crime and judicial issues), and the possible answers a respondent may choose to the questions are also general and simplistic in essence. Some criminological examples of poll data surveys are: "Should abortion be illegal?-Yes/No/Don't know", or "Do you support the death penalty for murderers?-Yes/No/Don't know".

Although this kind of surveys usually provides important insights, as is the case during political election campaigns, most of them suffer from severe shortcomings. First, although both the issues covered by such surveys, and the attitudes toward them, are usually heterogeneous and complex, many public opinion polls-and as a result empirical studies based on them-call for general, simplistic homogeneous responses (e.g., yes/no; agree/disagree) to very complex questions, stated in simple terms. Second, control questions about similar objects (for comparison with respondents' other answers) are usually not included, so the information provided by the respondents is limited. Third, and specific to the field of crime, many studies reveal that people have stereotypical images of crimes and offenders, when they evaluate criminal situations. Accordingly, if important features of these situations are not included in the surveys (for example, such as offenders' and victims' characteristics), respondents may fill them in themselves automatically, threatening the internal validity of the research (e.g., Applegate, Wright \& Dunaway, 1994 [35]; Durham, Elrod \& Kinkade, 1996 [36]; Finkel, 1995 [37]; Jacoby \& Cullen, 1999 [38]; Roberts, 1992 [39]).

\subsection{The Simple Scenario Approach}

Due to these aforementioned limitations, social scientists introduced some decades ago the simple scenario approach, to provide respondents with a more complex rating task, one that more closely approximates the information available in real-life situations, and that leaves less room for personal interpretative variation.

The basis of this approach is that instead of the simplistic, abstract, general questions applied in poll surveys, it provides the respondents with a short, concrete story-scenario or vignette-for evaluation. For example, instead of asking the respondents, "What in your opinion is the seriousness of a burglary?," as done by the poll data design, a scenario on a burglary will state, "At night, a man sneaks through a window into a stranger's apartment, steals from it money and jewels, and leaves the place the same way that he entered." (e.g., Sitren \& Applegate, 2006 [40]; Viki, Chiroro \& Abrams, 2006 [41]; Witting, Furuno \& Hirshon, $2006[42])$. 
As probably evident, the scenarios approach provides the respondents with better descriptions of reality, including also in the criminological field. Second, although reported attitudes do not necessarily translate into actual behavior, research on social psychology reveals that as the object for evaluation is more specific and clear-as it is at the scenario approach-, then the relationship between attitude and behavior is reinforced (e.g., Fazio, Powell \& Herr, 1983 [43]; Kraus, 1995 [44]). ${ }^{5}$ Due to its advantages, this technique has been used widely in criminological research, among other also in assessing public perceptions of the seriousness of a variety of offenses (see O'Connell \& Whelan, 1996 [47]; Rossi et al., 1974 [48]; Sellin \& Wolfgang, 1964 [49]; Wolfgang et al., 1985 [50]).

However, one of the main weaknesses of the simple scenario approach is that it does not allow for the systematic and simultaneous examination of the effects of multiple contextual factors surrounding, and also within the scenarios, that may influence public attitudes toward it (e.g., Applegate et al., 1994 [35]; Jacoby \& Cullen, 1999 [38]; Roberts, 1992 [39]; Rossi \& Berk 1997 [51]). Thus, the simple scenario approach suffers from a limited content domain, when all respondents evaluate the same scenarios, and second, from maturation over a fixed question sequence (Denk et al. 1997 [52]). Thus, under the simple scenario approach, the characteristics of the evaluated object are constant (identical in all the scenarios), and not at all variables. Thus we cannot analyze their influence on the respondents' attitudes.

\subsection{The Factorial Survey Approach}

Because of the aforementioned disadvantages of the simple scenario approach, the factorial design methodology has been developed; generally speaking, it retains the advantages of the former approach, but in addition also overcomes its disadvantages. On the one hand, the factorial design method also uses short scenarios, such as described under the former approach. On the other, and here is the innovation, unlike the former approach, it uses multidimensional scenarios, presented in a form that combines the benefits of controlled, randomized experimental designs and conventional surveys (e.g., Rossi \& Anderson, 1982 [53]; Rossi \& Berk, 1997 [51]; Rossi, Simpson \& Miller, 1985 [54]).

Generally speaking, the scenarios used by this approach are created by randomly selecting values (levels) from each of several variables (dimensions) - one level per dimension per scenario-, until each dimension is represented in the scenario, and a complete scenario is formed. For example, within a hypothetical crime scenario, chosen randomly from a variety of possible offenses, the offender's and victim's personal characteristics, such as their sex (male or female), ethnicity (e.g., white or black) and age (e.g., 25 or 50 years old), and also the consequences of the offense (very hard or much less), are chosen randomly. In this

\footnotetext{
${ }^{5}$ In this regard, in order for attitudes to predict behavior, research on social psychology reveals that: the two have to refer to the same level of specificity (see Fishbein \& Ajzen, 1975 [45]); the longer the time between attitude measurement and the measurement of behavior, the more likely is that the attitude will change, and so the two will become mismatched (Fishbein \& Coombs, 1974 [46]); and the stronger one's attitudes are, the more likely they are to have an influence on behavior.
} 
way, a factorial scenario is finally created. Accordingly, unlike the aforementioned simple scenario approach to a burglary, a factorial scenario of this offense will state, for example: "At night, a 25-year-old white man sneaks through a window into the apartment of a 50-year-old white woman, steals money and jewels worth NIS 10,000, and leaves the place the same way that he entered." Accordingly, unlike the former scenario approach, the factorial technique allows the researcher to analyze which information pieces of those randomly introduced within the scenarios-for example, offender's age, gender, ethnicity, worth of the stolen property-have influence, and in which direction, on the respondents' judgment of them.

Note that in studies which already applied the factorial approach, all evaluated scenarios do not constitute at all the research population, available from the universe of all possible levels across the chosen dimensions. In fact, they represent a random sample of all possible created scenarios. Although (statistically) two identical scenarios could happen to be evaluated by different respondents, due to the multiplicity of stimulus combinations there is a high probability of each evaluated scenario being unique. Moreover, due to their complete randomization, the scenarios' variables cannot covary, either with respondents' personal (demographic) characteristics, or with themselves (e.g., Denk et al., 1997 [52]). This feature, although far from the situation in reality, in which characteristics of the evaluated objects tend to covary with themselves or with respondents' characteristics, constitutes another advantage of this approach.

Rossi and Anderson (1982 [53]), among the founders of this approach, note that by permitting multiple dimensions of a crime scenario to vary randomly across scenarios, and by controlling respondents' personal characteristics-for example, by regression analyses-, this technique allows for the exploration of the effects of several independent and control variables simultaneously, while permitting unbiased estimates of the contributions of each of them to the overall judgment of the respondent (see also Rossi et al., 1985 [54]). Note also that this possibility of controlling both scenario variables and respondent's characteristics seems to be decisive, particularly when the studied phenomena are complex and multidimensional. First, it may be expected in these cases that some variables related to these scenarios (e.g., offenders' and victims' personal characteristics; characteristics of the offense) will exert considerable influence on respondents' attitudes to them, affirming the old saw "the devil being in the details" (Finkel, Burke \& Chavez, 2000: p. 1133 [55]). Second, specifying and controlling for values of independent variables in scenario questions also ensures greater internal validity, and ensures that respondents are exposed to the same "treatment". And third, as in many other social science fields, criminological attitudes will presumably also be affected by respondents' characteristics, hence the importance of controlling for them too. Thus the factorial survey approach is more rigorous than attitudinal research conducted using poll data, or simple scenarios, and in my opinion, it should be considered to be of a higher quality research design that either of these methods. 
Moreover, the literature on social psychology also learns that possessing more information about an attitude object, such as this provided by the factorial scenarios, in comparison with the other less developed methods, leads to greater attitude strength and behavioral consistency (Chaiken, Pomerantz \& Giner-Sorolla, 1995 [56]). Given these advantages, this method has already been applied to examine various criminological and sociological issues (e.g., Rossi \& Berk, 1997 [51]; Rossi et al., 1985 [54]), such as crime seriousness (e.g., Herzog, 2007a [57]; 2007b [58]; 2008 [59]; and Oreg, 2008 [60]).

\section{The Present Study: Application to Crime Seriousness}

Only as an illustration, and to show the main differences between the survey techniques, and convince the reader of the experimental character of the factorial-survey approach, these techniques are here applied generally to the field of crime seriousness studies. Note that similar patterns of findings may be obtained from any other-criminological—field.

Briefly, criminologists and sociologists have long been interested in public perceptions of the seriousness of different types of criminal offenses; their systematic analysis has featured as an important topic in social science research for the last 40 years. Among its contributions, this area of research helps shed light on individual, group, and societal reactions to, and evaluations of, crime, cultural belief systems, and the role of law in society (e.g., Levi \& Jones, 1985 [61]; O'Connell \& Whelan, 1996 [47]).

This topic has become a particularly common research area since the publication of the influential work by Sellin and Wolfgang (1964 [49]), The Measurement of Delinquency, in which samples of students, police officers, and judges were requested to evaluate the seriousness of 141 criminal offenses. ${ }^{6}$

Despite the wide diversity of these studies, consensus in respondents' seriousness perceptions across different social sectors and population groups can be consistently identified. Crimes of violence-i.e., homicide, rape, and interpersonal violence-are usually perceived by respondents, regardless of social and cultural variation, as the most serious offenses. Only after these come-often in much the same order-property, white-collar, and victimless offenses. Interestingly, comparable findings have emerged in most of these studies, regardless of scaling method (e.g., Levi \& Jones, 1985 [61]; O’Connell \& Whelan, 1996 [47]; Sellin \& Wolfgang, 1964 [49]; Walker, 1978 [64]), and despite the types of samples and respondents compared, within the same nation (e.g., Levi \& Jones, 1985 [61]; Rossi et al., 1974 [48]; Sellin \& Wolfgang, 1964 [49]) and also cross-culturally (e.g., Evans \& Scott, 1984 [62]; Newman, 1976 [65]).

These consensual findings have many implications. On the theoretical level they are often cited in support of the consensus model of the criminal law-as opposed to the conflict model-, which assumes a close match between the atti-

${ }^{6}$ That research has been successfully replicated in various formats, periods of time, and cultural samples (e.g., Evans \& Scott, 1984 [62]; Levi \& Jones, 1985 [61]; Newman, 1976 [65]; Rossi et al., 1974 [48]; van Dijk \& van Kesteren, 1996 [63]; Wolfgang et al., 1985 [50]). 
tudes of various social groups to both the definition of certain acts as criminal offenses and their perceived seriousness (see Rossi \& Henry, 1980 [66]; Thomas, Cage \& Foster, 1976 [67]; Warr, Gibbs \& Erickson, 1982 [68]). If different social groups, both within a given society and cross-culturally, reach very similar rankings of offenses based on their seriousness, this tends to show modern societies as functional unities, whose elements, despite some cultural differences, share important perspectives. In the context of public policy these common public opinions have led in some situations to political justification of differential levels of punishment for different offenses and of unequal distribution of resources by the criminal justice system. Accordingly, the greater punishments and resources set, for example, for the investigation and prosecution of murder and other violent offenses, as against the lesser investment of human and economic resources in police investigation and in the prosecution of victimless and moral offenses, have been justified based on consensually common opinion (e.g., Heller \& McEwen, 1975 [69]; Levi \& Jones, 1985 [61]; O’Connell \& Whelan, 1996 [47]).

\section{Research Site}

It should be noted that the three studies presented in the following were conducted in Israel. This country is seen as well suited for the analysis of seriousness perceptions of many criminal offenses for various reasons:

1) most studies in this area have been conducted in the United States and Britain, and only few elsewhere, specifically in Israel.

2) The findings of the few crime seriousness studies conducted in Israel (e.g., Herzog, 2003 [70]; 2006 [71]), are very similar to those found in the literature; hence the suitability of Israel as a research location for such an analysis.

3) Israel's population is multicultural, with many diverse religious and ethnic groups. Important social groups, traditionally under-represented and even ignored in other samples of Western countries, are well represented in this population, for example, a Jewish majority and an Arab (mostly Muslim) minority.

\section{Method of the Studies}

As noted, this article details the findings of three independent studies conducted by the author in the same criminological field-crime seriousness studies-but with different survey techniques: poll data, simple scenario, and factorial survey (hereinafter, first, second, and third studies).

The research data of the three studies appearing in this article were collected from various large, representative, random, national samples of the adult Israeli population ( $\mathrm{n}=743,987$, and 1,650 respectively); this feature increases considerably the possible generalization of the findings to the whole Israeli adult population. The most recent Israeli telephone directories at the time of each study, covering all geographical regions, provided the sampling framework, and the application of a systematic random sampling method assured identical probability of inclusion of all households listed-no other technique, such as interview 
schedule, was applied in any of the studies. ${ }^{7}$ Overall, these three samples show a close fit to the official data on the Israeli adult population.

In the three studies, respondents' seriousness perceptions of criminal offenses were collected by anonymous questionnaires, administered by means of telephone surveys ${ }^{8}$ - response rates: relatively high: 68,76 and 63 percent, respectively; interview length $7-10$ minutes. Due to the use of the telephone survey, each questionnaire (in each study) was relatively short, and included different randomly chosen offenses for evaluation: only four offenses in the first study, four in the second, and five in the third. The offenses evaluated by respondents in the first study appear in Table 1; the scenarios of the second study are detailed in Appendix 1; the variables and values of the factorial approach applied in the third study are detailed in Appendix 2. In addition, the last part of each questionnaire included several questions seeking demographic information about the respondents. The language of the questionnaires was kept as simple as possible, and the students who served as surveyors were carefully trained by the researcher to minimize potential bias. ${ }^{9}$

\section{Research Variables}

In the three studies, respondents were asked to judge each offense appearing in his/her questionnaire subjectively by evaluating its perceived seriousness-by selecting a value from a Likert-like scale ranging from $1=$ "Not serious at all" to 11 = "Very serious". Hence, the seriousness scores assigned to the offense constituted the dependent variables (criterion) of the research. To increase the uniformity of the evaluative task, respondents in the three studies were told at the beginning of the interviews that the described situations referred to acts defined as criminal offenses in Israel, and their responses should be based on their personal evaluation of the seriousness of the situations, and not on their knowledge of the legal situation in Israel (see Rossi et al., 1974 [48]; Sellin \& Wolfgang, 1964 [49]; Warr, 1989 [72]). Nevertheless, the possibility that the respondents' evaluations of the offenses were affected by the prevailing law cannot be excluded (see Blumstein \& Cohen, 1980 [73]); nevertheless it is assumed that most of the

\footnotetext{
${ }^{7}$ According to formal data of the Israeli Ministry of Communications (personal communication), 98 percent of Israel households are connected to the phone system. Based on these data, the percentage of people unlisted in the directories seems to be fairly low.

${ }^{8}$ The advantages of this survey method include having access to a large number of respondents in a relatively short period of time, the relative ease of obtaining broad, nationally representative samples, at a relatively low cost, ease of standardizing responses for comparison, minimal danger of the researcher biasing the respondents, and high level of anonymity. Prior to completion of the surveys, respondents were assured that confidentiality and anonymity of their responses would be maintained.

${ }^{9}$ The questionnaires were written in Hebrew but translated into Arabic and Russian for these minority groups. The response rates were calculated on the basis of valid household numbers, excluding businesses, fax connections, etc. To boost response rates, respondents who could not be reached initially were contacted again. A household was replaced after three unsuccessful attempts. Because the household's owner, whose name appears in the telephone directory, was not necessarily the person who answered the survey, the questionnaires remained anonymous. The questionnaires were also pre-tested with a small number of respondents in order to obtain an initial test of the measures' reliability and to test for any unexpected response patterns-none was found.
} 
Table 1. Comparison of the mean rating and ranking of the seriousness of some criminal offenses, by kind of applied research.

\begin{tabular}{|c|c|c|c|c|c|c|c|}
\hline \multicolumn{8}{|c|}{ Kind of study } \\
\hline \multirow[t]{2}{*}{ Criminal offenses } & \multicolumn{2}{|c|}{$\begin{array}{c}\text { First study: } \\
\text { Poll data }\end{array}$} & \multicolumn{2}{|c|}{$\begin{array}{l}\text { Second study: } \\
\text { Crime scenarios }\end{array}$} & \multicolumn{2}{|c|}{$\begin{array}{l}\text { Third study: } \\
\text { Factorial survey }\end{array}$} & \multirow[b]{2}{*}{ Sig. } \\
\hline & Mean & $\mathrm{SD}$ & Mean & SD & Mean & SD & \\
\hline Rape & 10.54 & 0.45 & 10.49 & 1.06 & 10.11 & 1.55 & \\
\hline Intimate murder & 10.36 & 0.38 & 10.37 & 0.67 & 9.97 & 2.25 & \\
\hline Acquaintance murder & - & - & 10.24 & 1.38 & 10.10 & 1.61 & \\
\hline Vehicular homicide & - & - & - & - & 9.40 & 1.84 & \\
\hline Ideological murder & - & - & 9.88 & 2.24 & - & - & \\
\hline Concealing evidence & - & - & 9.49 & 2.15 & - & - & \\
\hline Drug selling & 9.64 & 0.73 & 9.41 & 1.75 & 8.92 & 2.39 & * \\
\hline Shop arson & - & - & 9.31 & 2.40 & - & - & \\
\hline Trafficking in women & - & - & - & - & 8.63 & 2.23 & \\
\hline Shop robbery & 9.53 & 1.67 & 9.26 & 2.11 & 8.33 & 2.42 & * \\
\hline Apartment burglary & 9.23 & 1.80 & 8.91 & 2.29 & 8.14 & 2.31 & * \\
\hline Domestic violence & 9.18 & 0.84 & 8.80 & 2.12 & 8.55 & 2.49 & * \\
\hline Acquaintance violence & - & - & - & - & 8.36 & 2.66 & \\
\hline Threat to witness & - & - & 8.76 & 2.20 & - & - & \\
\hline Inflated bill & - & - & 8.04 & 2.56 & - & - & \\
\hline False testimony & - & - & 8.04 & 2.68 & - & - & \\
\hline Clerk bribe & - & - & 7.95 & 2.72 & 7.92 & 2.40 & \\
\hline Shoplifting & 8.24 & 2.37 & 7.82 & 2.66 & 7.48 & 2.70 & * \\
\hline Illegal sexual relations & - & - & 7.48 & 3.16 & - & - & \\
\hline Illegal abortion & - & - & 7.01 & 3.32 & - & - & \\
\hline Tax evasion & 7.37 & 2.69 & 6.18 & 2.97 & 5.17 & 3.12 & * \\
\hline
\end{tabular}

${ }^{*} \mathrm{p}<0.05$.

respondents had no knowledge of the formal stipulations of Israeli criminal law. Respondents were also informed that there were no right or wrong answers, and that they should give their honest reactions to the described situations.

Because this research set out to compare the findings of three seriousness studies, differing in the survey technique applied, the kind of survey techniquepoll data, simple scenario, or factorial survey-constituted the first independent variable (predictor) in this research. Moreover, to compare public perceptions of the seriousness of various criminal offenses, the type of offense represented in the questionnaire formed the second independent variable in the three studies. Based on repeated criticism of the over-representation of violent offenses in some seriousness studies (e.g., Cullen, Link, Travis, \& Wozniak, 1985 [74]; Miethe, 1982 [75]), the offenses described in the three studies were highly diverse, 
ranging from very grave-e.g., murder-to very minor-theft of a watch-, and included offenses of many kinds-violent, property, economic, white-collar, judicial, and victimless. These offenses were randomly chosen from a large pool of offenses representing the population of criminal offenses in Israel. Note that the number of evaluated offenses varied in the three studies. The least number of offenses-eight-were evaluated in the poll data (first) study; when crime scenarios were presented for evaluation (second study) 18 different offenses were evaluated. In the factorial-survey study 13 different offenses were randomly introduced into the scenarios that respondents were asked to evaluate. ${ }^{10}$

Although, as stated, it was assumed that Israeli respondents might not be familiar with the possible actual punishment of offenders, to avoid influencing them the name of the offenses was not specifically mentioned in the questions of the second and third studies. By contrast, in the first study (poll data), the respondents were asked to determine to which extent specific (named) criminal offenses were serious. In addition to the offense, and to enhance specificity, the crime scenarios in the second and third studies also included background information on the offenders and their victims (see Appendix 2; also Blum-West, 1985 [76]; Walker, 1978 [64]). Despite the use of the factorial-design methodology in the third study, some characteristics were kept uniform across all the evaluated offenses in the three studies: first, all the acts were described in such a way that there could be no question as to the responsibility of the offenders and the consequences of their deeds. Second, because logic suggests that any increase in the number of offenders and victims would significantly affect the perceived gravity of the incident, all the offenses involved a single offender and a single victim.

\section{Data Analysis}

Table 1 presents the means and standard deviations of the perceived seriousness (dependent variable) of the evaluated offenses in the three seriousness studies in this research (independent variables). For ease of understanding, the offense values appear in descending order of seriousness, according to the ranking of the whole sample of respondents in the second (wider) study.

The next step was to show how the seriousness values (dependent variable) in the three studies (independent variables) were distributed among the different control variables in this study: respondents' characteristics and scenario dimensions. Because this could be done for every common offense evaluated in the three studies, and to conserve space, I choose to exemplify it with a single offense, shoplifting. This offense was chosen because according to the data presented in Table 1, out of the offenses with a victim-unlike victimless offenses-, and in order to use the scenario variables related to the crime's victim in the

\footnotetext{
${ }^{10}$ Decisions regarding the number of variables to include in each scenario and the number of offenses to present to each respondent were pre-tested and guided by methodological considerations, such as the use of a telephone survey, interview length, full understanding of the scenarios, and allowing sufficient observations for each research condition to achieve sufficient statistical power for the data analyses.
} 
third study, it had the widest standard deviation and showed the greatest heterogeneity in the various control variables related to the respondents. Hence, Table 2 presents the means and standard deviations of the seriousness (dependent) variables, given by the respondents in the whole sample only to the various shoplifting offenses, while controlling for the several control variables of the research: respondents' details and scenario variables. The statistical comparisons between the different conditions-t-, F- and Pearson's tests-are also included here. Please note that the same analysis could be done with the other offenses.

Table 2. Mean ratings of the perceived seriousness of the "shoplifting" offense by respondents' personal details (three studies) and scenario variables (only third study).

\begin{tabular}{|c|c|c|c|c|c|c|c|c|c|c|}
\hline \multicolumn{11}{|c|}{ Kind of study } \\
\hline \multirow{2}{*}{ Variables } & \multirow{2}{*}{ Values } & \multicolumn{3}{|c|}{$1^{\text {st }}$ study: Poll data } & \multicolumn{3}{|c|}{$2^{\text {nd }}$ study: Scenarios } & \multicolumn{3}{|c|}{$3^{\text {rd }}$ study: Factorial } \\
\hline & & Mean & SD & Sig. & Mean & SD & Sig. & Mean & SD & Sig. \\
\hline \multicolumn{2}{|c|}{ All questions on shoplifting } & 8.24 & 2.37 & - & 7.82 & 2.66 & - & 7.48 & 2.70 & - \\
\hline Respondent's & Female & 8.30 & 2.21 & - & 8.07 & 2.37 & - & 7.64 & 2.58 & - \\
\hline Sex & Male & 8.19 & 2.21 & & 7.69 & 2.28 & & 7.52 & 2.46 & \\
\hline Respondent's & Jewish & 8.34 & 2.15 & * & 8.29 & 2.32 & * & 7.54 & 2.72 & * \\
\hline Ethnicity & Arab & 7.75 & 2.18 & & 7.53 & 2.42 & & 7.02 & 2.64 & \\
\hline Respondent's & Secular & 8.11 & 2.53 & - & 7.73 & 2.33 & - & 7.39 & 2.66 & - \\
\hline Religiosity & Trad./religious & 8.31 & 2.07 & & 7.93 & 2.34 & & 7.64 & 2.47 & \\
\hline Resp's status & Native born/veteran & 8.57 & 2.18 & * & 8.10 & 2.78 & * & 7.74 & 2.48 & * \\
\hline in the country & New immigrant & 7.47 & 2.09 & & 7.44 & 2.47 & & 6.90 & 2.56 & \\
\hline Resp's monthly & Less than NIS 5,000 & 7.87 & 2.34 & - & 7.99 & 2.13 & - & 7.73 & 2.65 & - \\
\hline familial income & More than NIS 5,000 & 8.40 & 2.07 & & 7.83 & 2.63 & & 7.46 & 2.40 & \\
\hline \multicolumn{2}{|c|}{ Resp's age (in years) } & \multicolumn{2}{|c|}{0.013} & - & \multicolumn{2}{|c|}{0.072} & - & \multicolumn{2}{|c|}{0.078} & - \\
\hline \multicolumn{2}{|c|}{ Resp's education (in schooling years) } & \multicolumn{2}{|c|}{-0.030} & - & \multicolumn{2}{|c|}{-0.054} & - & \multicolumn{2}{|c|}{0.010} & - \\
\hline Offender's & Female & - & - & - & - & - & - & 7.33 & 2.53 & * \\
\hline Sex & Male & - & - & & - & - & & 7.72 & 2.50 & \\
\hline Victim's & Female & - & - & - & - & - & - & 8.10 & 2.35 & * \\
\hline Sex & Male & - & - & - & - & - & - & 7.00 & 2.29 & \\
\hline Offender's & Jewish & - & - & - & - & - & - & 7.45 & 2.56 & - \\
\hline Ethnicity & Arab & - & - & - & - & - & - & 7.86 & 2.37 & \\
\hline Victim's & Jewish & - & - & - & - & - & - & 7.90 & 2.34 & - \\
\hline Ethnicity & Arab & - & - & - & - & - & - & 7.84 & 2.12 & \\
\hline Offender's & 25 years & - & - & - & - & - & - & 7.13 & 2.29 & - \\
\hline Age & 50 years & - & - & - & - & - & - & 7.65 & 2.96 & \\
\hline Victim's & 25 years & - & - & - & - & - & - & 7.90 & 2.36 & - \\
\hline Age & 50 years & - & - & - & - & - & - & 8.05 & 2.14 & \\
\hline Offender's & Yes & - & - & - & - & - & - & 8.31 & 2.34 & * \\
\hline crim. Record & (Not stated) & - & - & - & - & - & - & 7.37 & 2.32 & \\
\hline
\end{tabular}

${ }^{*} \mathrm{p}<0.05$. 
The influence of these control variables on the seriousness values (dependent variable) given to the evaluated offenses were also analyzed by multivariate OLS regression models, while controlling for both respondents' personal characteristics-all three studies-and the scenario dimensions-third study only. Table 3 presents the standardized regression coefficients and standard errors of respondents' characteristics in the first two studies only; Table 4 presents the same for the third study, in which the scenario dimensions (independent variables) were also added to the regression models-seriousness values: dependent variable.

Table 3. Standardized regression coefficients for the seriousness of evaluated criminal offenses among the whole samples in only the first and second studies, by respondents' personal details.

\begin{tabular}{|c|c|c|c|c|c|c|c|c|c|}
\hline Control var. ${ }^{1}$ Offenses & $\begin{array}{l}\text { Resp's } \\
\text { gender }\end{array}$ & $\begin{array}{l}\text { Resp's } \\
\text { age }\end{array}$ & $\begin{array}{l}\text { Resp's } \\
\text { educ. }\end{array}$ & $\begin{array}{l}\text { Resp's } \\
\text { income }\end{array}$ & $\begin{array}{l}\text { Resp's } \\
\text { ethnicity }\end{array}$ & $\begin{array}{l}\text { Resp's } \\
\text { relig. }\end{array}$ & $\begin{array}{l}\text { Resp's } \\
\text { status }\end{array}$ & $\begin{array}{c}\text { Valid } \\
\mathrm{N}\end{array}$ & $\mathbf{R}^{2}$ \\
\hline \multicolumn{10}{|l|}{$1^{\text {st }}$ study: Poll data } \\
\hline Rape & $-0.083^{\star}$ & 0.016 & 0.032 & -0.043 & $-0.182^{*}$ & $-0.116^{*}$ & $-0.130^{\star}$ & 186 & $0.037^{\star}$ \\
\hline Intimate murder & $-0.122^{\star}$ & 0.052 & 0.001 & 0.035 & $-0.121^{*}$ & -0.022 & $-0.130^{*}$ & 186 & $0.054^{*}$ \\
\hline Drug selling & $-0.072^{\star}$ & 0.027 & $-0.082^{\star}$ & -0.057 & $0.153^{*}$ & $0.150^{*}$ & -0.027 & 186 & $0.094^{\star}$ \\
\hline Shop robbery & -0.070 & -0.008 & -0.018 & -0.044 & $-0.148^{*}$ & 0.076 & -0.045 & 186 & $0.034^{*}$ \\
\hline Apartment burglary & -0.058 & 0.012 & -0.021 & $-0.099^{*}$ & $-0.158^{\star}$ & 0.029 & -0.028 & 186 & $0.038^{*}$ \\
\hline Domestic violence & $-0.156^{*}$ & -0.051 & $0.097^{*}$ & 0.034 & $-0.342^{*}$ & $-0.097^{\star}$ & $-0.101^{\star}$ & 186 & $0.215^{*}$ \\
\hline Shoplifting & -0.059 & 0.014 & -0.071 & -0.080 & $-0.142^{*}$ & $-0.086^{*}$ & $-0.112^{*}$ & 186 & $0.059^{*}$ \\
\hline Tax evasion & -0.068 & 0.049 & 0.021 & -0.051 & $-0.196^{*}$ & -0.025 & $0.094^{*}$ & 186 & $0.057^{*}$ \\
\hline \multicolumn{10}{|l|}{$2^{\text {nd }}$. Study: Scenarios } \\
\hline Rape & $-0.065^{\star}$ & 0.038 & 0.040 & -0.033 & $-0.221^{\star}$ & 0.014 & $-0.092^{*}$ & 247 & $0.063^{*}$ \\
\hline Intimate murder & $-0.095^{\star}$ & 0.001 & 0.043 & 0.071 & $-0.250^{\star}$ & 0.023 & 0.000 & 247 & $0.075^{*}$ \\
\hline Acqu. murder & 0.001 & -0.025 & 0.042 & -0.065 & -0.056 & 0.017 & 0.003 & 247 & 0.013 \\
\hline Ideological murder & -0.042 & 0.030 & 0.023 & $-0.079^{*}$ & 0.069 & -0.017 & $-0.129^{*}$ & 247 & $0.024^{*}$ \\
\hline Concealing evidence & -0.005 & -0.071 & 0.004 & 0.045 & $-0.268^{*}$ & 0.041 & -0.032 & 247 & $0.053^{*}$ \\
\hline Drug selling & $-0.093^{*}$ & -0.009 & $-0.089^{*}$ & 0.021 & $0.133^{*}$ & $0.100^{*}$ & -0.050 & 247 & $0.078^{*}$ \\
\hline Shop arson & -0.037 & $-0.111^{*}$ & 0.008 & $0.089^{*}$ & $-0.365^{*}$ & 0.030 & $-0.071^{\star}$ & 247 & $0.102^{*}$ \\
\hline Shop robbery & -0.060 & -0.051 & -0.029 & 0.015 & $-0.109^{\star}$ & 0.033 & $-0.089^{*}$ & 247 & $0.019^{*}$ \\
\hline Apartment burglary & $-0.101^{\star}$ & -0.016 & 0.001 & -0.013 & $-0.106^{*}$ & 0.032 & -0.040 & 247 & $0.023^{*}$ \\
\hline Domestic violence & $-0.156^{*}$ & -0.042 & $0.118^{*}$ & 0.021 & $-0.331^{\star}$ & -0.046 & $-0.089^{*}$ & 247 & $0.196^{*}$ \\
\hline Threat to witness & $-0.129^{\star}$ & 0.025 & 0.054 & -0.029 & 0.026 & 0.055 & -0.125 & 247 & $0.036^{*}$ \\
\hline Inflated bill & -0.058 & -0.038 & -0.056 & $0.072^{*}$ & $-0.184^{*}$ & 0.069 & $-0.197^{\star}$ & 247 & $0.060^{*}$ \\
\hline False testimony & $-0.098^{\star}$ & 0.018 & 0.008 & $-0.123^{*}$ & -0.072 & 0.058 & -0.053 & 247 & $0.034^{*}$ \\
\hline Clerk bribe & 0.014 & $0.099^{*}$ & 0.014 & -0.033 & $-0.117^{\star}$ & $0.079^{*}$ & $-0.106^{*}$ & 247 & $0.029^{*}$ \\
\hline Shoplifting & $-0.069^{\star}$ & 0.043 & -0.006 & -0.047 & $-0.141^{\star}$ & $-0.102^{*}$ & $-0.105^{\star}$ & 247 & $0.065^{*}$ \\
\hline Illegal sex. relations & $-0.086^{\star}$ & $0.120^{*}$ & 0.030 & -0.033 & 0.039 & $0.147^{*}$ & $-0.118^{\star}$ & 247 & $0.050^{*}$ \\
\hline Illegal abortion & $-0.114^{*}$ & $0.084^{*}$ & $-0.099^{*}$ & -0.012 & $0.114^{*}$ & $0.205^{\star}$ & $-0.125^{\star}$ & 247 & $0.134^{*}$ \\
\hline Tax evasion & -0.060 & $0.075^{\star}$ & -0.006 & -0.051 & $-0.133^{\star}$ & 0.034 & -0.047 & 247 & $0.033^{*}$ \\
\hline
\end{tabular}

${ }^{*} \mathrm{p}<0.05 ;{ }^{1}$ Variables' values: Gender $(0=$ female; $1=$ male), Age (interval, in years), Education (interval, in schooling years), Income $(0=$ less than NIS $5,000 ; 1=$ more $)$, Ethnicity $(0=$ Jewish; $1=$ Arab $)$, Religiosity $(0=$ secular; $1=$ traditional/religious $)$, Status in the country $(0=$ natives $/$ veterans; $1=$ new immigrant). 
Table 4. Standardized coefficients for the seriousness of criminal offenses (third study), by respondents' personal characteristics and scenario variables, for the whole sample of respondents.

\begin{tabular}{|c|c|c|}
\hline Variables & Values & B \\
\hline \multirow[t]{12}{*}{ Criminal offenses ${ }^{1}$} & Acquaintance murder & -0.018 \\
\hline & Intimate murder & -0.023 \\
\hline & Vehicular homicide & -0.061 \\
\hline & Drug selling & $-0.148^{\star}$ \\
\hline & Trafficking in women & $-0.163^{*}$ \\
\hline & Domestic violence & $-0.156^{*}$ \\
\hline & Acquaintance violence & $-0.162^{\star}$ \\
\hline & Shop robbery & $-0.178^{*}$ \\
\hline & Apartment burglary & $-0.172^{\star}$ \\
\hline & Clerk bribe & $-0.180^{*}$ \\
\hline & Shoplifting & $-0.179^{\star}$ \\
\hline & Tax evasion & $-0.244^{\star}$ \\
\hline Offender's gender & $0=$ Male $; 1=$ Female & $-0.125^{*}$ \\
\hline Victim's gender & $0=$ Male $; 1=$ Female & $0.087^{*}$ \\
\hline \multirow[t]{2}{*}{ Offender's ethnicity ${ }^{2}$} & Jewish & -0.025 \\
\hline & Arab & 0.036 \\
\hline \multirow[t]{2}{*}{ Victim's ethnicity ${ }^{2}$} & Jewish & 0.038 \\
\hline & Arab & -0.032 \\
\hline \multirow[t]{2}{*}{ Offender's age ${ }^{2}$} & 25 years & 0.026 \\
\hline & 50 years & -0.017 \\
\hline \multirow[t]{2}{*}{ Victim's age $^{2}$} & 25 years & -0.005 \\
\hline & 50 years & 0.027 \\
\hline Offender's crim. record & $0=$ not stated $1=$ Yes & $0.078^{\star}$ \\
\hline Respondent's sex & $0=$ male $; 1=$ female & 0.030 \\
\hline Respondent's age & Interval & 0.002 \\
\hline Respondent's education & Interval & -0.027 \\
\hline Respondent's income & $0=>$ NIS $5,0001=+$ & 0.038 \\
\hline Respondent's ethnicity & $0=$ Jewish; 1 = Arab & $-0.058^{*}$ \\
\hline Respondent's religiosity & $0=\sec ; 1=$ trad.$/$ relig. & 0.043 \\
\hline Resp.'s status in the country & $0=$ natives $/$ veterans; $1=$ immigrants & $-0.069^{*}$ \\
\hline \multirow[t]{3}{*}{ Model data } & Valid n & 1,637 \\
\hline & $\mathbf{R}^{2}$ & $0.281^{*}$ \\
\hline & Constant & $10.63^{*}$ \\
\hline
\end{tabular}

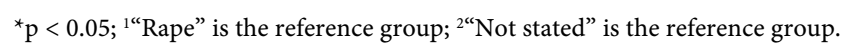


In this context of regression analyses, note the potential response bias in respondents' judgments due to the fact that each of them responded to several questions and the latter were treated in this study as units of analysis (see Hox, Kreft \& Hermkins, 1991 [77]). To overcome this possible problem, the regression analyses were also conducted using Hierarchical Linear Models software, which takes this possible problem into consideration. These latter analyses yielded findings very similar to the former; to conserve space only the OLS data are presented.

\section{Results}

From Table 1 we learn that irrespective of the kind of survey technique applied, some violent offenses-murder, rape and homicide-received the highest relative mean seriousness scores in the three studies (and in most cases the smallest standard deviations); thus respondents in the three studies ranked them as the most serious offenses considered. At the other extreme of the ranking, victimless offenses-tax evasion, illegal abortion, and illegal consensual sexual relations with a minor-received the lowest means (and the largest standard deviations) among the respondents in the three studies; accordingly, these acts were ranked in the three studies as the least serious offenses.

Beyond this similarity in the offenses' ranking, differences in the offenses' rating were evident from the comparison of the three studies. Obviously, such a comparison was not possible for every evaluated offense: the studies differed in the kind and number of offenses they included. But where this comparison was possible, in all cases the seriousness means were relatively higher in the firstpoll data-study than in the second-simple scenarios-study, where they were relatively higher than in the third study, taking the factorial-survey approach.

Like Table 1, Table 2 also shows that the respondents assigned the shoplifting offense relatively low seriousness means-between 8.24 and 7.48, out of a maximum of 11 -and standard deviations were wide-between 2.37 and 2.70-, denoting heterogeneity in respondents' attitudes to it. This table also reveals that many of the respondents' personal details (all three studies) and the scenario variables (third study) controlled for in this research had no significant effect on these perceptions. The only exceptions among respondents' characteristics were respondents' ethnicity and status in the country-Arabs and respondents born outside Israel (new immigrants) gave shoplifting significantly lower seriousness scores than the others.

A similar picture may be seen from the analysis of the scenario control variables, applied only on the third study, the factorial survey. From all the variables randomly introduced into the shoplifting scenarios, the only three that revealed some influence on respondents' judgments were, on the one hand, those specifically related to offenders' and victims' sex-offenses committed by female offenders and against female victims were perceived by the respondents as significantly less and more serious-respectively-than other parallel scenarios, and on the other hand, offenses committed by offenders having criminal 
records were perceived as significantly more serious than offenses in which details of the offenders' criminal records were not stated. The other randomly introduced variables in the scenarios appeared not to have exercised a significant influence on respondents' subjective judgments.

Table 3 shows that several respondents' characteristics affected a number of their judgments of seriousness in the first two studies; the regression coefficients for every respondent's characteristic showed a significant coefficient (for at least one of the evaluated offenses). However, deeper perusal showed that among these characteristics, those views were affected mainly by the respondents' ethnicity and status in the country, and mainly for victimless offenses, also by respondents' religiosity.

Interestingly, although the evaluated offenses differed in their core characteristics and modus operandi, Arab respondents tended to give almost all the evaluated offenses significantly lower seriousness scores than Jewish respondents. The only exceptions were drug selling and illegal abortions, to which Arab respondents gave significantly higher seriousness scores than their Jewish counterparts. Concerning new immigrants, the picture is more uniform: they tended to give almost all the offenses evaluated in the two studies significantly lower seriousness scores than their counterparts. For victimless offenses, such as illegal abortion and illegal sexual relations, more religious respondents gave these offenses significantly more serious scores.

Table 4, which focuses on the findings of the third study, shows that even when both scenario dimensions as well as respondents' characteristics are taken into account, many of the values of the offenses represented in the scenarios yielded significant positive regression coefficients. Compared with rape (the most serious offense; reference group), the seriousness perceptions of the other offenses were significantly lower. The strength of the significant coefficients increased linearly with decrease in perceived seriousness.

Other control variables also showed significant coefficients, some even reflecting a stronger effect on respondents' attitudes than some of the aforementioned values of the first independent variable. Among them, scenarios describing a female offender were perceived as significantly less serious that parallel scenarios in which the sex of the offender was not stated. By contrast, scenarios describing a female victim were perceived as significantly more serious than parallel scenarios in which the sex of the victim was not stated. Also, when information about the offender's previous criminal record was added these scenarios were perceived as significantly more serious than parallel scenarios that did not offer this information. Finally, concerning the influence of respondents' characteristics, this table too showed that both Arab and immigrant respondents perceived the scenarios as significantly less serious than the other respondents (religiosity was close to be significant).

\section{Discussion}

As previously stated, a review of the articles published in the leading crimino- 
logical journals so far reveals that for a highly qualified experimental study in criminology—and criminal justice - to be published—at least in these journals-, in most cases it needs to deal with a behavioral measure, which for the purposes of these studies will be considered the dependent variable (criterion). Unlike this situation, the purpose of the present study was to introduce the factorial-survey technique as an additional highly qualified experimental technique, which unlike the former situations may be applied in answering questions related to attitudinal issues in both criminology and criminal justice. To this end this research presented findings of three independent seriousness studies, conducted by three different survey techniques-poll data, simple scenario, and factorial surveyapplied to the same substantial attitudinal field, namely seriousness perceptions. According to the findings shown in Table 1, similar rankings of offenses with regard to their perceived seriousness were achieved regardless of the kind of survey technique applied. In each study, violent offenses (murder, rape, homicide) received the highest means-and usually the smallest standard deviationsand were ranked as the most serious offenses. Please note that although rape was considered the most serious offense, no significant differences were found, first, between it and other very serious offenses-homicide in general and some particular forms of murder, and second, between the rating values given to these serious offenses by the various survey techniques. After them, in the three studies, came property, white-collar, and victimless offenses. At the other extreme of seriousness, victimless offenses (tax evasion, illegal abortion, sexual relations with a minor, and/or bribery) received the lowest means-and usually the largest standard deviations; hence they were ranked as the least serious offenses. These findings may be considered as clearly supporting the theoretical consensus model of the criminal law, which assumes close identity in perspectives among diverse social groups (e.g., Rossi \& Berk, 1997 [51]; Rossi \& Henry, 1980 [66]; Thomas et al., 1976 [67]; Warr et al., 1982 [68]). Moreover, this table also shows that when a certain offense was perceived as relatively more serious, its high seriousness mean was usually accompanied by low standard deviations; hence the high consensus regarding the perceived high seriousness of violent offenses (see Cullen, Fisher \& Applegate, 1985 [74]; Levi \& Jones, 1985 [61]; O’Connell \& Whelan, 1996 [47]). As previously stated, comparable findings emerged in most crime seriousness studies (e.g., Evans \& Scott, 1984 [62]; Levi \& Jones, 1985 [61]; Newman, 1976 [65]; O’Connell \& Whelan, 1996 [47]; Rossi et al., 1974 [48]; Sellin \& Wolfgang, 1964 [49]; Walker, 1978 [64]).

Apparently, and only apparently, it may be concluded from this paragraph that all three types of detailed studies found pretty much the same findings, even though the factorial approach has been suggested to be more rigorous. However, as detailed later, this impression is only temporal, and other differences will be added later.

Although similar rankings of offenses have been reached regardless of the type of survey technique applied, this research shows that differences in rating are evident from the comparison between the various studies: as the survey technique 
was more developed and rich, public attitudes were significantly less serious and more heterogeneous. This finding was mainly seen for the rating of middleranking and relatively non-serious offenses-serious offenses were considered as very serious regardless of the applied survey technique-, and is also compatible with other findings in the literature: research tends to show that respondents tend to be less homogeneous and unequivocal when they are presented with more information for their evaluation, and when more sophisticated survey methods are used (see Applegate et al., 1996 [78]; Doob \& Roberts, 1983 [79]; Durham et al., 1996 [36]; Roberts, 1992 [39]). For example, and only as example, see the findings in research on public support for the use of the death penalty in the US: a common finding in this area of research is that as the survey is more developed and rich, and the respondents are confronted with the details of specific cases, the respondents' views tend to be less homogeneous and severe than when they are answering a general question (see for example, Cullen et al., 2000 [80]; Murray, 2003 [81]).

The research findings, regardless of the type of survey applied, also showed high consistency concerning the influence of respondents' characteristics on their seriousness perceptions of a relatively non-serious offense-shoplifting. As shown in Table 2, although several of these characteristics were taken into account, and different survey techniques were applied in the various studies, the same variables appeared to influence respondents' attitudes to shoplifting in all three studies. In them, Arab and new immigrant respondents perceived this offense as significantly less serious than their counterparts-i.e., Jewish and nativeborn or veteran respondents. Although it may be considered as a non-advantage of the factorial approach, it is in my opinion another advantage of it: the influence of respondents' characteristics on their attitudes was not related to the kind of survey being applied, and it remains steady on all the studies.

Interestingly, greater permissiveness or tolerance toward offenses does not seem to reflect lower social status within Israeli society. Although Arab, religious, immigrant and/or female Israelis are located in the relatively lower social strata of Israeli society, and are mostly absent from dominant circles, in contrast to others, their seriousness perceptions do not show a common pattern. Accordingly, it seems to be apt to analyze the differences in rating between Israeli groups separately, in the context of each social division (see Herzog, 2006 [71]).

However, Table 2 also shows that compared with the poll data and simple scenario, only the more sophisticated factorial survey allows empirical analysis of the influence-and lack of influence-of pieces of information within the scenario on respondents' judgments of them. As previously explained, these bits of information were randomly selected for each scenario (e.g., Rossi \& Anderson 1982 [53]; Rossi \& Berk 1997 [51]; Rossi et al., 1985 [54]). This random choice of scenario dimensions transforms this technique from a simple scenario approach to a distinctly entire experimental technique, in which respondents are randomly allocated and exposed to the several-survey-situations they are requested to evaluate. Accordingly, as in other experimental techniques, if significant differ- 
ences are found among the different research conditions in the dependent variable-seriousness perceptions-, it may be concluded, at a relatively high level of certainty, that they stem from the different conditions-different combinations of scenario variables-to which the respondents were exposed during the study.

Another advantage of this experimental approach is the possibility of analyzing empirically which of these scenario dimensions influence respondents' attitudes, in which direction, and which do not. On the one hand, from Table 2 we learn that out of these randomly introduced scenario dimensions in shoplifting situations, only those concerning the sex of both the offender and victim, and the existence of a criminal record of the offender, significantly affected respondents' seriousness perceptions of this offense. These findings are compatible with others in the literature showing that male offending, female victimization, and/or offender's criminal history, are related to higher public seriousness and punitiveness (see Applegate et al., 1996 [78]; Blumstein \& Cohen, 1980 [73]; Cullen et al., 2000 [80]; McCorkle, 1993 [82]; Roberts, 1992 [39]). Among them, in the author's opinion, the sex variables concerning offending are the most interesting for future research. Previous works show that female suspects and offenders tend to receive more lenient treatment by the criminal justice system than male offenders who have committed the same crimes. To explain such sex-based discrimination, chivalry theory has arisen as the primary theoretical framework. It suggests that protective and benevolent societal attitudes to women lead decision makers-predominantly male-throughout the criminal justice system to take a relatively lenient approach to female offenders. Empirical research has tended to support the existence of such an approach (see Daly \& Tonry, 1997 [83]; Spohn, 1999 [84]; Steffensmeier, Kramer \& Streifel, 1993 [85]), both generally and also applied to women who perform offenses that are "typically female", such as petty thefts and shoplifting (e.g., Farnworth \& Teske, 1995 [86]; Johnson \& Scheuble, 1991 [87]; Scheider, 2000 [88]). In this regard, the factorial-survey approach may be applied to consider the evaluator's perspective of a crime situation as a potential source of differential treatment of male and female offending.

On the other hand, Table 2 also shows that the inclusion of information concerning the ethnicity of both the offenders and victims in the shoplifting situation does not influence respondents' views of this offense significantly. This finding is particularly interesting, based on accumulated empirical evidence supporting the perspectives that first, people generally have stereotypical pictures of typical crime events and their perpetrators (Blum-West, 1985 [76]; Lynch \& Danner, 1993 [89]; Roberts, 1992 [39]), and second, the race or the ethnicity of offenders, especially regarding the "black-white" division-in the American context-and the "Jewish-Arab" division-in the Israeli context-, plays an important part in the stereotypical crime images pictured by ordinary people (e.g., Herzog, 2003 [70]; Hurwitz \& Peffley, 1997 [90]; Poole \& Regoli, 1980 [91]; Stephan \& Rosenfield, 1982 [92]). As said, one of the various advantages of the factorial approach is to learn about the influence, and also lack of 
influence, of variables included in the scenarios. Accordingly, further research focusing more sharply on the offending of different kind of offenders, and in other contexts, is called for.

\section{Conclusions}

As stated, the main purpose of the present study was to show that unlike the current situation, at least as expressed by the publication state of most of the leading criminological journals, highly qualified randomized trials in criminology and criminal justice may be based on attitudinal, and not only behavioral, measures as dependent variables. In this regard, the purpose of the present study was to introduce the factorial-survey technique as an additional highly qualified experimental technique, which unlike the former situations, may be applied in answering questions related to attitudinal issues in both criminology and criminal justice.

In this regard, note that compared with the poll data and simple scenario, only the more sophisticated factorial survey allows empirical analysis of the influence -and also lack of influence-of pieces of information within the scenario on respondents' judgments of them. As previously explained, these bits of information were randomly selected for each scenario (e.g., Rossi \& Anderson, 1982 [53]; Rossi \& Berk, 1997 [51]; Rossi et al., 1985 [54]). This random choice of scenario dimensions transforms this technique from a simple scenario approach to a distinctly entire experimental technique, in which respondents are randomly allocated and exposed to the several-survey-situations they are requested to evaluate. Accordingly, as in other experimental techniques, if significant differences are found among the different research conditions in the dependent variable-for example, seriousness perceptions-, it may be concluded, at a relatively high level of certainty, that they stem from the different conditions-different combinations of scenario variables-to which the respondents were exposed during the study.

Another advantage of this experimental approach is the possibility of analyzing empirically which of these scenario dimensions influence respondents' attitudes, in which direction, and which do not. For example, out of some randomly introduced scenario dimensions in crime situations, only some of them significantly tend to affect respondents' seriousness perceptions of this offense. In this regard, the factorial-survey approach may be applied, for example, to consider the evaluator's perspective of a crime situation as a potential source of differential treatment of male and female offending (see Herzog \& Oreg, 2008 [60]).

On the other hand, note that the inclusion of additional information in the scenario-for example, concerning the ethnicity of both the offenders and victims-does not necessarily influence respondents' views of this offense, at a significant level. This kind of non-significant findings, and not only the significant ones, may be particularly interesting, based on accumulated empirical evidence supporting the perspectives that, first, people generally have stereotypical pictures of typical crime events and their perpetrators (e.g., Blum-West, 1985 [76]; 
Lynch \& Danner, 1993 [89]; Roberts, 1992 [39]), and second, the race or the ethnicity of offenders, especially regarding the "black-white" division in the American context, usually plays an important part in the stereotypical crime images pictured by ordinary people (e.g., Herzog, 2003 [70]; Hurwitz \& Peffley, 1997 [90]; Poole \& Regoli, 1980 [91]; Stephan \& Rosenfield, 1982 [92]).

As conclusion, it may be said that one of the various advantages of the factorial approach is to learn about the influence, and also lack of influence, of variables included in the scenarios. Accordingly, further research focusing more sharply on the various details of an offense situation, also of other sociological and psychological situations, and also in other cultural and/or social contexts, is called for.

Finally, despite the aforementioned advantages of the factorial approach that overcome theoretical and methodological obstacles, its limitations need to be taken into account when analyzing its benefits. Basically, this technique tends to be based on short hypothetical scenarios depicting typical (crime) situations. In this context, it may be assumed, on the one hand, that other factors not considered in these scenarios, such as additional characteristics of crime situations and persons involved in them, might influence the respondents' judgments. Hence, further analysis of questions and hypotheses raised by studies applying this technique, with more extensive descriptions of crime situations, offenders and victims is highly recommended.

\section{References}

[1] Hough, (2010) Gold Standard or Fool's Gold? The Pursuit of Certainty in Experimental Criminology. Criminology and Criminal Justice, 10, 11-22. https://doi.org/10.1177/1748895809352597

[2] Sampson, R. (2010) Gold Standard Myths: Observations on the Experimental Turn in Quantitative Criminology. Journal of Quantitative Criminology, 26, 489-500. https://doi.org/10.1007/s10940-010-9117-3

[3] Sherman, L. (2009) Evidence and Liberty: The Promise of Experimental Criminology. Criminology and Criminal Justice, 9, 5-28. https://doi.org/10.1177/1748895808099178

[4] Davis, R.C., Maxwell, C.D. and Taylor, B. (2006) Preventing Repeat Incidents of Family Violence: Analysis of Data from Three Field Experiments. Journal of Experimental Criminology, 2, 183-210. https://doi.org/10.1007/s11292-006-9002-0

[5] Goldkamp, J.S. and White, M.D. (2006) Restoring Accountability in Pretrial Release: The Philadelphia Pretrial Release Supervision Experiments. Journal of Experimental Criminology, 2, 143-181. https://doi.org/10.1007/s11292-006-9001-1

[6] Koehler, J.J. and Thompson, W.C. (2006) Mock Jurors' Reactions to Selective Presentation of Evidence from Multiple-Opportunity Searches. Law and Human Behavior, 30, 455-468. https://doi.org/10.1007/s10979-006-9021-4

[7] Matthieu, M. and Ivanoff, A. (2006) Treatment of Human-Caused Trauma: Attrition in the Adult Outcomes Research. Journal of Interpersonal Violence, 21, 1654 1664. https://doi.org/10.1177/0886260506294243

[8] Topalli, V. (2005) Criminal Expertise and Offender Decision-Making: An Experimental Analysis of How Offenders and Non-Offenders Differentially Perceive Social Stimuli. British Journal of Criminology, 45, 269-295. 
https://doi.org/10.1093/bjc/azh086

[9] Lum, C. and Yang, S. (2005) Why Do Evaluation Researchers in Crime and Justice Choose Non-Experimental Methods? Journal of Experimental Criminology, 1, 191 213. https://doi.org/10.1007/s11292-005-1619-x

[10] Ajzen, I. and Fishbein, M. (1980) Understanding Attitudes and Predicting Social Behavior. Prentice-Hall, Englewood Cliffs, NJ.

[11] Allport, G.W. (1968) The Person in Psychology. Beacon Press, Boston, MA.

[12] Calder, B.J. and Ross, M. (1973) Attitudes and Behavior. General Learning Press, Morristown, NJ.

[13] Wicker, A. W. (1969) Attitudes versus Actions: The Relationship of Verbal and Overt Behavioral Response to Attitude Objects. Journal of Social Issues, 25, 41-78. https://doi.org/10.1111/j.1540-4560.1969.tb00619.x

[14] Heingartner, A. and Hall, J.V. (1974) Affective Consequences in Adults and Children of Repeated Exposure to Auditory Stimuli. Journal of Personality and Social Psychology, 29, 719-723. https://doi.org/10.1037/h0036121

[15] Crandall, J.E. (1970) Preference and Expectancy Arousal: Further Evidence. Journal of General Psychology, 83, 268-297. https://doi.org/10.1080/00221309.1970.9710809

[16] Sawyer, A.G. (1981) Repetition, Cognitive Response, and Persuasion. In: Petty, R.E., Ostrom, T.M. and Brock, T.C., Eds., Cognitive Responses in Persuasion, Erlbaum, Hillsdale, NJ, 237-261.

[17] Pilner, P. (1982) The Effects of Mere Exposure on Liking for Edible Substances. Appetite, 3, 283-290. https://doi.org/10.1016/S0195-6663(82)80026-3

[18] Zajonc, R.B. (1968) Attitudinal Effects of Mere Exposure. Journal of Personality and Social Psychology, 9, 1-27. https://doi.org/10.1037/h0025848

[19] Olson, J.M. and Zanna, M.P. (1993) Attitudes and Attitude Change. Annual Review of Psychology, 44, 117-154. https://doi.org/10.1146/annurev.ps.44.020193.001001

[20] Zanna, M.P. and Rempel, J.K. (1988) Attitudes: A New Look at an Old Concept. In: Bar-Tal, D. and Kruglanski, A.W., Eds., The Social Psychology of Knowledge, Cambridge University Press, Cambridge, UK, 315-334.

[21] Ajzen, I. (1982) On Behaving in Accordance with One's Attitudes. In: Zanna, M., Higgins, E. and Herman, C., Eds., Consistency in Social Behavior. The Ontario Symposium, Erlbaum, Hillsdale, NJ, 3-15.

[22] Allport, G.W. (1935) Attitudes. In: Murchison, C., Ed., Handbook of Social Psychology, Clark University Press, Worcester, MA, 798-844.

[23] Thomas, W.I. and Znaniecki, F. (1918) The Polish Peasant in Europe and America. Vol. 1. Badger, Boston.

[24] Zanna, M.P. and Fazio, R.H. (1982) The Attitude-Behavior Relation: Moving toward a Third Generation of Research. In: Zanna, M.P., Higgins, E.T. and Herman, C.P., Eds., Consistency in Social Behavior. The Ontario Symposium (Vol. 2), Erlbaum, Hillsdale, NJ, 283-301.

[25] Fazio, R.H. (1986) How Do Attitudes Guide Behavior? In: Sorrentino, R.M. and Higgins, E.T., Eds., The Handbook of Motivation and Cognition: Foundation of Social Behavior, Guilford Press, New York, 204-243.

[26] Ajzen I. (1988) Attitudes, Personality, and Behavior. Dorsey, Chicago.

[27] Eagly, A.H. and Chaiken, S. (1993) The Psychology of Attitudes. Harcourt Brace Jovanovich, Fort Worth, TX.

[28] Mita, T.H., Dermer, M. and Knight, J. (1977) Reversed Facial Images and the Mere Exposure Hypothesis. Journal of Personality and Social Psychology, 35, 597-601. 
https://doi.org/10.1037/0022-3514.35.8.597

[29] Bornstein, R.F. (1989) Exposure and Affect: Overview and Meta-Analysis of Research, 1968-1987. Psychological Bulletin, 106, 265-289.

https://doi.org/10.1037/0033-2909.106.2.265

[30] Bargh, J.A. (1997) The Automaticity of Everyday Life. In: Wyer Jr., R.S., Ed., Advances in Social Cognition, Erlbaum, Mahwah, NJ, 1-61.

[31] Green, D.A. (2006) Public Opinion versus Public Judgment about Crime: Correcting the "Comedy of Errors". British Journal of Criminology, 46, 131-154. https://doi.org/10.1093/bjc/azi050

[32] Lynch, M.J., McGurrin, D. and Fenwick, M. (2004) Disappearing Act: The Representation of Corporate Crime Research in Criminological Literature. Journal of Criminal Justice, 32, 389-398. https://doi.org/10.1016/j.jcrimjus.2004.06.001

[33] Tyler, T.R. and Wakslak, C. (2004) Profiling and Police Legitimacy: Procedural Justice, Attributions of Motive, and Acceptance of Police Authority. Criminology, 42, 253-281. https://doi.org/10.1111/j.1745-9125.2004.tb00520.x

[34] Vollum, S., Longmire, D.R. and Buffington-Vollum, J. (2004) Confidence in the Death Penalty and Support for Its Use: Exploring the Value-Expressive Dimension of Death Penalty Attitudes. Justice Quarterly, 21, 521-546. https://doi.org/10.1080/07418820400095891

[35] Applegate, B., Wright, J.P. and Dunaway, R.G. (1994) Victim-Offender Race and Support for Capital Punishment: A Factorial Design Approach. American Journal of Criminal Justice, 18, 95-115. https://doi.org/10.1007/BF02887641

[36] Durham, A., Elrod, H.P. and Kinkade, P.T. (1996) Public Support for the Death Penalty: Beyond Gallup. Justice Quarterly, 13, 705-736. https://doi.org/10.1080/07418829600093161

[37] Finkel, N.J. (1995) Commonsense Justice: Jurors' Notions of the Law. Harvard University Press, Cambridge, MA.

[38] Jacoby, J. and Cullen, F. (1999) The Structure of Punishment Norms: Applying the Rossi-Berk Model. The Journal of Criminal Law and Criminology, 89, 245-307. https://doi.org/10.2307/1144222

[39] Roberts, J. (1992) Public Opinion, Crime and Criminal Justice. Crime and Justice: An Annual Review of Research, 16. University of Chicago Press, Chicago.

[40] Sitren, A.H. and Applegate, B.K. (2006) Intentions to Offend: Examining the Effects of Personal and Vicarious Experiences with Punishment and Punishment Avoidance. Journal of Crime \& Justice, 29, 25-50. https://doi.org/10.1080/0735648X.2006.9721647

[41] Viki, G.T., Chiroro, P. and Abrams, D. (2006) Hostile Sexism, Type of Rape, and Self-Reported Rape Proclivity within a Sample of Zimbabwean Males. Violence against Women, 12, 789-800. https://doi.org/10.1177/1077801206291663

[42] Witting, M.D., Furuno, J.P. and Hirshon, J.M. (2006) Support for Emergency Department Screening for Intimate Partner Violence Depends on Perceived Risk. Journal of Interpersonal Violence, 21, 585-596. https://doi.org/10.1177/0886260506286841

[43] Fazio, R., Powell, M.C. and Herr, P.M. (1983) Toward a Process Model of the Attitude-Behavior Relation: Accessing One's Attitude upon Mere Observation of the Attitude Object. Journal of Personality and Social Psychology, 44, 723-735. https://doi.org/10.1037/0022-3514.44.4.723

[44] Kraus, S.J. (1995) Attitudes and the Prediction of Behavior: A Meta-Analysis of the Empirical Literature. Personality and Social Psychology Bulletin, 21, 58-75. 
https://doi.org/10.1177/0146167295211007

[45] Fishbein, M. and Ajzen, I. (1975) Belief, Attitude, Intention, and Behavior: An Introduction to Theory and Research. Addison-Wesley, Reading, MA.

[46] Fishbein, M. and Coombs, F.S. (1974) Basis for Decision: An Attitudinal Analysis of Voting Behavior. Journal of Applied Social Psychology, 4, 95-124. https://doi.org/10.1111/j.1559-1816.1974.tb00662.x

[47] O’Connell, M. and Whelan, A. (1996) Taking Wrongs Seriously: Public Perceptions of Crime Seriousness. British Journal of Criminology, 36, 299-318. https://doi.org/10.1093/oxfordjournals.bjc.a014087

[48] Rossi, P., Waite, E., Bose, C.E. and Berk, R.E. (1974) The Seriousness of Crimes: Normative Structure and Individual Differences. American Sociological Review, 39, 224-237. https://doi.org/10.2307/2094234

[49] Sellin, T. and Wolfgang, M. (1964) The Measurement of Delinquency. Wiley, New York.

[50] Wolfgang, M., et al. (1985) The National Survey of Crime Severity. U.S. Government Printing Office, Washington DC.

[51] Rossi, P. and Berk, R. (1997) Just Punishments: Federal Guidelines and Public Views Compared. Aldine de Gruyter, New York.

[52] Denk, C.E., Benson, J.M., Fletcher, J.C. and Reigel, T.M. (1997) How Do Americans Want to Die? A Factorial Vignette Survey of Public Attitudes about End-of-Life Medical Decision-Making. Social Science Research, 26, 95-120. https://doi.org/10.1006/ssre.1996.0587

[53] Rossi, P. and Anderson, A. (1982) The Factorial Survey Approach: An Introduction. In: Rossi, P. and Nock, S., Eds., Measuring Social Judgments. The Factorial Survey Approach, Sage, Beverly Hills, CA, 1-25.

[54] Rossi, P., Simpson, J. and Miller, J. (1985) Beyond Crime Seriousness: Fitting the Punishment to the Crime. Journal of Quantitative Criminology, 1, 59-89. https://doi.org/10.1007/BF01065249

[55] Finkel, N., Burke, J.E. and Chavez, L.J. (2000) Commonsense Judgments of Infanticide: Murder, Manslaughter, Madness, or Miscellaneous? Psychology, Public Policy, and Law, 6, 1113-1137. https://doi.org/10.1037/1076-8971.6.4.1113

[56] Chaiken, S., Pomerantz, E.M. and Giner-Sorolla, R. (1995) Structural Consistency and Attitude Strength. In: Petty, R.E. and Krosnick, J.A., Eds., Attitude Strength: Antecedents and Consequences, Erlbaum, Mahwah, NJ, 387-412.

[57] Herzog, S. (2007) Public Perceptions of Sexual Harassment: An Empirical Analysis in Israel from Consensus and Feminist Theoretical Perspectives. Sex Roles, October issue, 579-592. https://doi.org/10.1007/s11199-007-9220-6

[58] Herzog, S. (2007) An Empirical Test of Feminist Theory and Research: The Effect of Heterogeneous Gender-Role Attitudes on Perceptions of Intimate Partner Violence. Feminist Criminology, 2, 223-244. https://doi.org/10.1177/1557085107301836

[59] Herzog, S. (2008) An Attitudinal Explanation of Biases by Criminal Justice Agents: An Empirical Testing of Defensive Attribution Theory. Crime and Delinquency, 54, 457-481. https://doi.org/10.1177/0011128707308158

[60] Herzog, S. and Oreg, S. (2008) Individual Differences in Crime Seriousness Judgments: Chivalry and the Moderating Effect of Ambivalent Sexism. Law \& Society Review, 42, 45-74. https://doi.org/10.1111/j.1540-5893.2008.00334.x

[61] Levi, M. and Jones, J. (1985) Public and Police Perceptions of Crime Seriousness in England and Wales. British Journal of Criminology, 25, 234-250. 
[62] Evans, S. and Scott, J. (1984) The Seriousness of Crime Cross-Culturally: The Impact of Religiosity. Criminology, 22, 39-59. https://doi.org/10.1111/j.1745-9125.1984.tb00287.x

[63] van Dijk, J. and van Kesteren, J. (1996) The Prevalence and Perceived Seriousness of Victimization by Crime: Some Results of the International Crime Victims Survey. European Journal of Crime, Criminal Law and Criminal Justice, 4, 48-70. https://doi.org/10.1163/157181796X00122

[64] Walker, M. (1978) Measuring the Seriousness of Crimes. British Journal of Criminology, 18, 348-364.

[65] Newman, G. (1976) Comparative Deviance: Perception and Law in Six Cultures. Elsevier, New York.

[66] Rossi, P. and Henry, P. (1980) Seriousness: A Measure for All Purposes? In: Klein, M. and Teilmann, K., Eds., Handbook of Criminal Justice Evaluation, Sage, Beverly Hills, CA.

[67] Thomas, C., Cage, R. and Foster, S. (1976) Public Opinion on Criminal Law and Legal Sanctions: An Examination of Two Conceptual Models. Journal of Criminal Law and Criminology, 67, 110-116. https://doi.org/10.2307/1142462

[68] Warr, M., Gibbs, J. and Erickson, M. (1982) Contending Theories of Criminal Law: Statutory Penalties versus Public Preferences. Journal of Research in Crime and Delinquency, 19, 25-46. https://doi.org/10.1177/002242788201900103

[69] Heller, N. and McEwen, T. (1975) Applications of Crime Seriousness Information in a Police Department. Journal of Research in Crime and Delinquency, 12, 44-50. https://doi.org/10.1177/002242787501200105

[70] Herzog, S. (2003) Does the Ethnicity of Offenders in Crime Scenarios Affect Public Perceptions of Crime Seriousness? A Randomized Survey Experiment in Israel. Social Forces, 82, 757-781. https://doi.org/10.1353/sof.2004.0011

[71] Herzog, S. (2006) Public Perceptions of Crime Seriousness: A Comparison of Social Divisions in Israel. Israel Law Review, 39, 57-80. https://doi.org/10.1017/S0021223700012917

[72] Warr, M. (1989) What Is the Perceived Seriousness of Crimes? Criminology, 27, 795-821. https://doi.org/10.1111/j.1745-9125.1989.tb01055.x

[73] Blumstein, A. and Cohen, J. (1980) Sentencing of Convicted Offenders: An Analysis of the Public's View. Law and Society Review, 14, 233-261. https://doi.org/10.2307/3053313

[74] Cullen, F., Link, B., Travis, L. and Wozniak, J. (1985) Consensus in Crime Seriousness: Empirical Reality or Methodological Artifact? Criminology, 23, 99-118. https://doi.org/10.1111/j.1745-9125.1985.tb00328.x

[75] Miethe, T. (1982) Public Consensus on Crime Seriousness: Normative Structure or Methodological Artifact? Criminology, 20, 515-526. https://doi.org/10.1111/j.1745-9125.1982.tb00475.x

[76] Blum-West, S. (1985) The Seriousness of Crime: A Study of Popular Morality. Deviant Behavior, 6, 83-98. https://doi.org/10.1080/01639625.1985.9967661

[77] Hox, J.J., Kreft, I. and Hermkins, P. (1991) The Analysis of Factorial Surveys. Sociological Methods and Research, 19, 493-510. https://doi.org/10.1177/0049124191019004003

[78] Applegate, B., et al. (1996) Determinants of Public Punitiveness toward Drunk Driving: A Factorial Survey Approach. Justice Quarterly, 13, 57-79.

https://doi.org/10.1080/07418829600092821 
[79] Doob, A. and Roberts, J. (1983) An Analysis of the Public's Views of Sentencing. Department of Justice, Ottawa.

[80] Cullen, F., Fisher, B. and Applegate, B. (2000) Public Opinion about Punishment and Corrections. In: Tonry, M., Ed., Crime and Justice: A Review of Research, University of Chicago Press, Chicago, Vol. 27. https://doi.org/10.1086/652198

[81] Murray, G.R. (2003) Raising Considerations: Public Opinion and the Fair Application of the Death Penalty. Social Science Quarterly, 84, 753-770. https://doi.org/10.1046/j.0038-4941.2003.08404018.x

[82] McCorkle, R. (1993) Research Note: Punish and Rehabilitate? Public Attitudes toward Six Common Crimes. Crime \& Delinquency, 39, 240-252. https://doi.org/10.1177/0011128793039002008

[83] Daly, K. and Tonry, M. (1997) Gender, Race and Sentencing. In: Tonry, M., Ed., Crime and Justice: A Review of Research, University of Chicago Press, Chicago, Vol. 22, 201-242. https://doi.org/10.1086/449263

[84] Spohn, C. (1999) Gender and Sentencing of Drug Offenders: Is Chivalry Dead? Criminal Justice Policy Review, 9, 365-399.

[85] Steffensmeier, D., Kramer, J. and Streifel, C. (1993) Gender and Imprisonment Decisions. Criminology, 31, 411-446. https://doi.org/10.1111/j.1745-9125.1993.tb01136.x

[86] Farnworth, M. and Teske Jr., R. (1995) Gender Differences in Felony Court Processing: Three Hypotheses of Disparity. Women and Criminal Justice, 6, 23-44. https://doi.org/10.1300/J012v06n02 02

[87] Johnson, D.R. and Scheuble, L.K. (1991) Gender Bias in the Disposition of Juvenile Court Referrals: The Effects of Time and Location. Criminology, 29, 677-699. https://doi.org/10.1111/j.1745-9125.1991.tb01084.x

[88] Scheider, M.C. (2000) Moving Past Biological Determinism in Discussions of Women and Crime during the 1870s-1920s: A Note Regarding the Literature. Deviant Behavior, 21, 407-427. https://doi.org/10.1080/01639620050085825

[89] Lynch, J. and Danner, M. (1993) Offense Seriousness Scaling: An Alternative to Scenario Methods. Journal of Quantitative Criminology, 9, 309-322.

https://doi.org/10.1007/BF01064464

[90] Hurwitz, J. and Peffley, M. (1997) Public Perceptions of Race and Crime: The Role of Racial Stereotypes. American Journal of Political Science, 41, 375-401. https://doi.org/10.2307/2111769

[91] Poole, E. and Regoli, R. (1980) Race, Institutional Rule-Breaking, and Disciplinary Response: A Study of Discretionary Decision Making in Prison. Law and Society Review, 14, 931-946. https://doi.org/10.2307/3053215

[92] Stephan, W. and Rosenfield, D. (1982) Racial and Ethnic Stereotypes. In: Miller, A., Ed., The Eye of the Beholder. Contemporary Issues in Stereotyping, Praeger, 92136. 


\section{Appendix 1. Offense Scenarios Presented to Respondents in the Second Study and Corresponding Offenses}

Scenario description

1. A 35-year-old Arab man suspects that his wife is cheating on him. Therefore, after taking his children to school, and being alone with her, he stabs her several times, causing her immediate death.
Offense

Intimate (wife) murder

2. A 32-year-old Arab businessman files income tax returns declaring a lower income than the actual one.

False tax declaration

3. At night, a 27-year-old Jewish man sneaks through a window into a stranger's apartment, steals money and jewels worth NIS 10,000, and leaves the place the same way that he entered.

Apartment burglary

4. A 48-year-old Arab man enters his home earlier than usual, discovers his wife in bed with another man. He beats her, causing her severe physical injury.

Intimate (wife) assault

5. A 46-year-old Jewish man is called to a police station to give evidence about a neighbor suspected of committing an offense. With the intention of protecting the neighbor, who did indeed commit the offense, he gives false evidence.

False testimony

6. A 27-year-old Jewish man invites a girl of his age out and, during the meeting, he compels her to have sexual relations with him. The girl opposes vigorously but is unable to overcome him.

Intimate (girl) rape

7. A 35-year-old Jewish man threatens to hurt his friend if he tells the police about an illegal act that he committed.

Threat to witness

8. In the setting of a political confrontation, a 28-year-old Arab man throws a petrol bomb into a Jewish shop in a neighboring settlement and causes it to burn down.

Shop arson

9. A 30-year-old Arab man sells marihuana and hashish from his home.

Drug selling

10. A 35-year-old Jewish man driving his car argues with an Arab driver about a parking place in a main street. During the argument the former pulls out a knife stabs the other in the chest, killing him instantaneously.

Non-planned (street) murder

11. A 30-year-old Arab man enters a jewelry shop and, at gunpoint, steals NIS 10,000 from the cash register.

Shop robbery

12. A 32-year-old Jewish man has sexual relations with a 15-year-old girl. The relations are consensual.

The man knows the girl's age.

Illegal sexual relations

13. A 42-year-old Arab doctor conducts illegal abortions in his private clinic.

Illegal abortion

14. During violent confrontations in the occupied territories, a 25-year-old Jewish man enters a coffee shop in an Arab settlement, throws a grenade, causing the immediate death of a man.

Ideological murder

15. A 45-year-old Jewish man enters a watchmaker's shop, looks at the shelves, and while nobody is looking, manages to slip a watch worth NIS 500 into his pocket. He leaves the shop without paying for it.

Watch theft

16. A 43 year-old Arab garage owner presents a bill to a client for car repairs including NIS 500 for car parts which in fact he did not replace.

Inflated bill - Fraud

17. A 45-year-old Jewish clerk working in a municipality gets NIS 10,000 from a contractor, and in return he helps him win a tender for building a new residential neighborhood in the city.

Clerk bribe

18. A 42-year-old Arab police officer conducts an investigation against a Jewish suspect. To win a conviction, he decides to hide evidence proving the suspect's innocence.

Concealing evidence 


\section{Appendix 2: Variables and Values in the Third (Factorial) Study}

\section{A. Criminal offense}

1. Intimate murder/ 2. Acquaintance murder/ 3. Domestic violence/ 4. Acquaintance violence/ 5. Rape/ 6. Vehicular homicide/ 7. Burglary/ 8. Shoplifting/ 9. Robbery/ 10. Trafficking in women/11. Tax evasion/12. Bribe/ 13. Drug selling

B. Offender's sex and C. Victim's sex

1. Male/2. Female

D. Offender's ethnicity and E. Victim's ethnicity

1. Jewish/2. Arab/3. (Not stated)

F. Offender's age and G. Victim's age

1. 25 years old $/ 2.50$ years old/3. (Not stated)

H. Offender's criminal record

1. Yes/2. (Not stated)

Sample scenarios:

1. A 25-year-old Jewish man with a criminal record illegally drove a 25-yearold woman from Russia to Israel and forced her to work as a prostitute against her will.

2. Due to suspicion of romantic betrayal, a 50-year-old Jewish man with a criminal record beat his girlfriend, a Jewish 25-year-old woman, seriously.

3. A 25-year-old Jewish man with a criminal record breaks into a 50-year-old Jewish woman's apartment through a window, and steals jewels and money worth NIS 10,000.

4. A 25-year-old Jewish housewife is shopping at a drugstore owned by a 50-year-old Jewish woman, and she slips a watch worth NIS 200 into her handbag and leaves the store without paying for it.

\section{Submit or recommend next manuscript to SCIRP and we will provide best} service for you:

Accepting pre-submission inquiries through Email, Facebook, LinkedIn, Twitter, etc. A wide selection of journals (inclusive of 9 subjects, more than 200 journals)

Providing 24-hour high-quality service

User-friendly online submission system

Fair and swift peer-review system

Efficient typesetting and proofreading procedure

Display of the result of downloads and visits, as well as the number of cited articles

Maximum dissemination of your research work

Submit your manuscript at: http://papersubmission.scirp.org/

Or contact jss@scirp.org 